\title{
O ELO PERDIDO, EM TRÊS MOVIMENTOS: O (NÃO-)LUGAR DA SOCIEDADE CIVIL EM TAVARes Bastos, Oliveira Viana e RAYMUNDO FAORO
}

\author{
Pedro Luiz Lima
}

\begin{abstract}
RESUMO
0 presente artigo busca tratar da convergência de narrativas históricas acerca da relativa ausência da sociedade civil no processo de formação sociopolítica do Brasil. A partir da leitura detida das obras de três autores-chave do pensamento político brasileiro - Tavares Bastos, Oliveira Viana e Raymundo Faoro -, investiga-se o modo como, mesmo nos dissonantes enquadramentos do liberalismo clássico da segunda metade do século XIX, do iberismo autoritário da primeira metade do século XX e do republicanismo liberal de décadas mais recentes, a reiteração do caráter lacunar da sociedade civil pautou seus diagnósticos e constituiu seus distintos projetos normativos.
\end{abstract}

Palavras-chave: Pensamento político brasileiro. Sociedade civil. Estado. Liberalismo.

\footnotetext{
${ }^{1}$ Doutorando em Ciência Política pelo IESP/UERJ e Professor do Departamento de Ciências Sociais da UEL. E-mail para contato: pedrollima@gmail.com
} 


\title{
THE MISSING LINK, IN THREE MOVEMENTS: CIVIL SOCIETY IN TAVARES Bastos, Oliveira Viana e RAYMUNDO FAORO
}

\begin{abstract}
The article deals with the relative absence of Civil Society in the historical accounts of different narratives on Brazil's sociopolitical formation. It investigates this convergence through a close reading of three key-authors from the Brazilian political thought tradition: Tavares Bastos, Oliveira Viana e Raymundo Faoro. In their seemingly antagonistic perspectives, this article argues that it is proficuous to highlight how the common topos of Civil Society's absence has determined their diagnosis and normative projects. As a consequence, this shared core blurs the distinctions between the traditional roots of Brazilian political thought, framing together the late nineteenth century's classical liberalism, the early twentieth century's authoritarian iberianism and the most recent liberal republicanism.
\end{abstract}

Keywords: Brazilian political thought. Civil society. State. Liberalism.

\section{INTRODUÇÃO}

narrativa hegeliana de formação do Estado moderno se constrói pela
negação de dois inimigos declarados. De um lado, é preciso superar a
tradição contratualista e seu dualismo estado de natureza - estado civil; de outro, há que transpor o abismo interposto pelo idealismo kantiano entre ideal e real.

Não se trata, aqui, de mero uso estilístico dos termos negação e superação. Em sua filosofia do direito, Hegel situa a moralidade subjetiva (a Moralität de Kant) no momento negativo, como elo intermediário a ser suprassumido entre 0 direito abstrato e a moralidade objetiva (Sittlichkeit). Por sua vez, o movimento interno à realização desta moralidade objetiva parte da família como um primeiro momento de imediatez e deve superar, necessariamente, a esfera da sociedade civil, lugar por excelência de negação da identidade comum e da abstração individualista, antes de culminar no Estado.

Opondo ao modelo bipartite dos contratualistas a forma triádica da dialética, Hegel aponta para um novo lugar da política - lugar este que, no jogo da superação-conservação intrínseco ao desenvolvimento dialético do real, está para além das relações particularistas da sociedade civil, a despeito de contê-la como um de seus momentos. A eticidade, real apenas no Estado, carece da sociedade 
civil para se fazer efetiva; entre a relação de pertencimento e integração imediata própria à família e a associação de caráter universal própria ao Estado, a sociedade civil deve, negando os primeiros laços integrativos, desenvolver as individualidades e particularidades em um sistema de carências onde cada um é meio para a realização de todos os outros.

São famosas, ademais, as passagens em que Hegel descreve "o espetáculo da devassidão" e da "miséria" (HEGEL, 2003, p. 169) que advém de um sistema de dependências recíprocas cuja base é o fim egoísta (HEGEL, 2003, p. 168). 0 importante é reter que não existe, no modelo hegeliano (modelo que, diga-se de passagem, não é mero artifício heurístico, visto que o racional é real), uma autonomia da política. 0 Estado, acima da sociedade civil, não a cancela, e nem pode passar sem ela. A sociedade civil figura, portanto, como um momento necessário na realização da eticidade.

Ora, é precisamente contra este imbróglio dialético que se dirige a crítica do jovem Marx. Em contraposição à concepção hegeliana de que o Estado deve ser e de fato é, a um só tempo, uma necessidade exterior e um fim imanente com relação à sociedade civil, Marx questiona a abstração que funda o Estado e, dando um passo decisivo rumo à fundamentação do seu materialismo histórico, encontra nesta sociedade civil "o verdadeiro lar, o verdadeiro cenário de toda a história” (MARX, 1980, p. 44).

Enquanto em Hegel o achatamento do dever ser no ser e a recusa do idealismo kantiano levam a uma apologética do Estado, em que não há outro lugar possível para a eticidade, em Marx, por seu turno, identifica-se o idealismo implícito na própria concepção hegeliana de um Estado pairando por cima e brotando do interior da sociedade civil - "0 Estado político, em relação à sociedade civil, é precisamente tão espiritual como o céu em relação à terra" (MARX, 1989, p. 45). A antinomia, em Marx, se revela não resolvida; a realização da eticidade persiste como um fim imanente à sociedade civil que, com efeito, ainda não se transmutou em necessidade exterior. Nesse ponto, o dever ser também reside no ser, dialeticamente como potência, e a superação do jogo individualista de interesses que determina a sociedade civil se abre para o futuro, carente de uma ruptura.

Chegamos, assim, através deste longo prelúdio, ao ponto que motivou desde 0 início toda a digressão: seja a sociedade civil momento necessário para realização da eticidade no Estado, seja ela o palco por excelência da História, o que fazer com uma história que não a conheceu? Em outros termos: e se a nossa história se revela desprovida de sociedade civil? Ou, pior ainda, e se tivermos a 
ingrata peculiaridade de termos os dois pólos do movimento dialético da moralidade objetiva, o familismo e o Estado, sem o elo necessário capaz de dar coerência ao todo?

Não são poucas as narrativas históricas sobre a formação do Brasil que convergem precisamente na constatação desta grande ausência. É, pois, sobretudo para lidar com uma convergência possível, entre alguns dos autores de um rol bastante amplo - que, um tanto paradoxalmente, colocam a ausência da sociedade civil como protagonista de suas leituras da história nacional -, que este artigo se volta para Tavares Bastos, Oliveira Viana e Raymundo Faoro. Não se trata, como veremos, de defender um parentesco teórico geral e irrestrito a aproximá$\operatorname{los}^{2}$. Pelo contrário, o objetivo aqui é realçar em que medida mesmo as dissonantes concepções de Tavares Bastos em relação a Oliveira Viana, por exemplo, contêm um nexo comum no que concerne à identificação daquele elo perdido. Todos os três, cada um à sua maneira, estão lidando com esta nossa dialética manca, ou com esta "não-história" (JASMIN, 2003, p. 361). Resta apenas saber como eles o fazem e de que forma encaram aquela hegeliana antinomia não resolvida em sua modulação à brasileira: se em Hegel, como denuncia Marx, a ambivalência de um Estado imanente-transcendente esconde o seu caráter de reflexo superestrutural, no Brasil destes três autores a antinomia se dá entre um Estado real e uma sociedade civil idealizada e concebida como projeto. Invertidos, assim, os termos da questão, vejamos qual o lugar da política e como o idealismo brasileiro ganha contornos ambivalentes.

Adotar a problemática da relação Estado-sociedade civil, tal como desenvolvida na crítica de Marx a Hegel, como ponto de partida não implica, evidentemente, que se procure traçar aqui uma vinculação imediata entre os conceitos marxianos e as ideias formuladas pelos três pensadores brasileiros de que nos ocuparemos mais detidamente. Mas, ressalva concedida, será através da mediação conceitual daquela problemática que se buscará melhor alinhavar as relações estabelecidas entre as diferentes interpretações do Brasil investigadas e, fundamentalmente, identificar a formação contraditória do nexo comum que as aproxima.

\footnotetext{
${ }^{2}$ Remetendo a Gildo Marçal Brandão, referência fundamental para a definição dos objetivos deste artigo, cabe enfatizar que "o esforço para desentranhar 'afinidades eletivas' entre pensadores e entre teorias, continuidades subterrâneas de longa duração e nem sempre percebidas pelos próprios autores-atores, etc., nada tem que ver com a busca de "matizes ideológicas transepocais'" (BRANDÃO, 2007, p. 54).
} 
Cabe ainda ressaltar o caráter "não-meramente-livresco" desta empreitada. Isto é, não se tratará aqui da simples busca por uma reconstrução a mais fidedigna possível dos termos ou das intenções dos autores estudados. Pois não apenas a própria dimensão reduzida deste artigo torna por si só proibitivo um tratamento devidamente "contextualista", como também o nosso propósito aqui extrapola os limites da minúcia histórica. É necessário, contudo, sublinhar que 0 sentido político imediato das obras analisadas emerge sob incontornável determinação do contexto em que foram escritas - de modo que o liberalismo federalista de um Tavares Bastos, por exemplo, só poderia ser apreendido em todas as suas nuances se vinculado à relativa hegemonia do projeto centralizador dos saquaremas ${ }^{3}$.

Para além disso, das intenções mais diretamente antiquaristas, retomar a questão da ausência da sociedade civil significa, a nosso juízo, entrar em um debate atual que permanece distante do esgotamento, sendo as consequências políticas da hegemonia de um certo tipo de teoria da ausência notavelmente pungentes para que esta seja lida acriticamente.

\section{FUGA: LIBERALISMO E IDEALISMO EM TAVARES BASTOS}

Reconhecido como um dos grandes publicistas liberais do Segundo Império, Tavares Bastos (1839-1875) tem muitas vezes o seu liberalismo confundido, pelos historiadores, com um idealismo americanista insensível às especificidades da história brasileira. Parece-nos mesmo que uma tendência simplificadora e dualista, que muitas vezes acomete a visão retrospectiva sobre a história, acaba por tomar a sua obra por uma simples repetição de idéias importadas. Nesse sentido, o dualismo historicista tornaria nosso século XIX mais inteligivel ao agrupar, de um lado, os liberais como idealistas portadores de idéias descabidas ao nosso meio, e de outro os conservadores como realistas com uma compreensão mais sociologicamente orientada do Brasil. Vejamos, no entanto, como 0 inegável americanismo de Bastos, uma vez apreendido em algumas de suas nuances, não se deixa confundir com o simplório liberalismo idealista de que muitas vezes lhe acusam ${ }^{4}$. Não apenas o liberalismo pode ser encontrado em um

\footnotetext{
${ }^{3}$ Para uma leitura do contexto de conflito entre os defensores da descentralização e os da centralização, ver "Centralização e descentralização no Império: o debate entre Tavares Bastos e visconde de Uruguai" (1999), de Gabriela Nunes Ferreira.

${ }^{4}$ Wanderley Guilherme dos Santos parece, por vezes, em seu clássico artigo, recair numa leitura simplificada do pensamento de Tavares Bastos. Diz o autor: "Liberais doutrinários são portanto as sucessivas facções de políticos e de analistas que, desde meados do século XIX, sustentaram a
} 
ou outro lado da cerca que separa luzias de saquaremas, como ainda o sentido do que seria idealismo nesta dicotomia merece a devida atenção.

Por decerto, Tavares Bastos pode ser lido como um pensador paradigmático da história brasileira na chave da ausência. Nesse sentido, ele é um dos primogênitos de uma filiação que um século depois teria em Raymundo Faoro um de seus principais expoentes. É curioso observar que, tanto para o autor de Os donos do poder quanto para o oitocentista, a ausência primeiro se revela como fardo legado pelo nosso passado ibérico. Passado que na verdade insiste, e aí a fonte dos males do presente, em se perpetuar e em impossibilitar um presente alternativo e, conseqüentemente, um futuro emancipado. Em certo sentido, nossa grande ausência aparece a Tavares Bastos como ausência de contemporaneidade; temos um passado que obstrui o presente - somos carentes de um presente, propriamente dito. Impossível não ver, anacronicamente, Faoro nestas linhas de Bastos:

Ilusão de patriotismo! A origem dos nossos males não está só nos recentes erros de ontem, como de ordinário se diz. Não! Para descobrila é preciso remontar ao curso de mais de um século, a muitos dias passados; é preciso procurá-la nesse longínquo tempo em que se encerrou a epopéia da idade-média e começou o drama terrível da história moderna (BASTOS, 1976, p. 29).

A miséria moral, como a pobreza material, não a compramos com a independência: herdamo-las. Colônia alguma recebeu de um povo europeu mais rico legado. Seja embora! As heranças veneram-se. Nós veneramos os nossos prejuízos. Nossa miséria histórica é a nossa riqueza. 0 passado instalou-se no presente, acompanha-0, excede-o, esconde-0, cobre-0, ele, uma sombra! 0 passado é a idéia inata dos governos e o critério da população. Aquele não ousa feri-lo de frente. Esta afere tudo pela medida das máximas consagradas (BASTOS, 1975, p. 4).

Contra o receio de anarquia que impregna seus contemporâneos, receosos de que o Brasil reproduza as histórias conturbadas e revolucionárias de seus

crença de que a reforma político-institucional no Brasil, como em qualquer lugar, seguir-se-ia naturalmente à formulação e execução de regras legais adequadas. A linhagem começou, talvez, com Tavares Bastos, no século XIX, que, fascinado pelo sistema americano, propôs insistentemente a descentralização, a autonomia provincial e a imigração livre" (SANTOS, 1978, p. 97). 
vizinhos hispânicos, Tavares Bastos afere que, antes destas ebulições sociais, devemos temer a paralisia de um Estado que se interpõe a qualquer mínimo movimento da sociedade civil, impedindo-a de efetivamente existir. Com efeito, 0 publicista não será de todo alheio àquelas preocupações; mas, como ele mesmo 0 afirma, aqui "não é tanto a impunidade do crime que se deve recear, mas antes a prepotência da autoridade" (BASTOS, 1937, p. 210). A anarquia da nossa vizinhança não deve obliterar a tarefa de transformação que se impõe face a uma ordem apenas aparente - "0 estado presente é que é a anarquia" (BASTOS, 1937, p. 126).

A ausência se transmuta em farsa, e o processo eleitoral é sua melhor expressão: um povo fictício confere uma legitimidade ornamental a seus pretensos representantes, que em verdade representariam pouco mais do que seu interesse particular, em manifesta colonização do público pelo privado.

Neste cenário, o governo é o portador solitário do dinamismo. Constatada a ausência do povo - a ausência de uma sociedade civil com o choque de interesses que lhe é característico -, não será para Tavares Bastos por meio de um construtivismo estatista que se preencherá a lacuna. 0 governo paternal, ou 0 Estado demiurgo, em sua inclinação construtivista, apenas alarga 0 vazio:

Assim: pedi que o governo seja só governo, que distribua justiça, mantenha a ordem, puna o crime, arrecade 0 imposto, represente 0 país; mas que não transponha a meta natural, mas que não se substitua à sociedade. É impossível, respondem. 0 governo, como no tempo do rei, deve presidir o povo, dirigir o povo, educar o povo, ensinar tudo ao povo, seu pupilo; isto é, percorrer a escala de todas as opressões sociais. E, com efeito, o governo paternal coloniza o país, lavra a terra, exerce o comércio, ampara a moral, sustenta a religião, regula tudo, submete tudo (BASTOS, 1975, p. 4).

Os efeitos antropológicos e morais desta tutela estatista são consideráveis. Um povo paralítico, que "tem escusa para tudo" (BASTOS, 1975, p. 42): eis o resultado da interferência inadequada do governo. 0 papel da política não é forjar, mas sim deixar desenvolver - papel eminentemente negativo. A crítica ferrenha de Tavares Bastos à centralização guarda relação fundamental com seus pressupostos antropológicos. Parte-se, pois, de uma defesa ontológica da liberdade, à qual a política deve se adequar, ou melhor, deve se submeter. Assim, tem-se em primeiro lugar que "o que caracteriza o homem é o livre arbítrio e o sentimento 
da responsabilidade que the corresponde. Suprimi na moral a responsabilidade, e a história do mundo perde todo o interesse que aviventa a tragédia humana." (BASTOS, 1975, p. 18). Como corolário, "para que um povo se aperfeiçoe e aumente em virtudes, é mister que seja livre” (BASTOS, 1975, p. 42).

Se é apenas na escola da liberdade que se pode suprir a nossa famigerada ausência, ganhando vida uma sociedade inerte e corrompida pela centralização, a função da política não está em dar vida a esta sociedade mas em deixá-la viver. A ausência da sociedade civil oculta, portanto, uma imanência pronta a aparecer na superfície da história, fosse o governo devidamente sábio e comedido em suas atribuições (VIANNA, 2004, p. 164). Em outros termos, na narrativa de Tavares Bastos, a sociedade civil é uma perene virtualidade, pronta a se desenvolver no real, bastando para isso que se limite o governo e o exagero centralizador, pólo irradiador de corrupção.

É curioso, para os fins da sequiência deste artigo, observar que 0 "brasileiro" de Tavares Bastos aproxima-se, em muitos aspectos, da descrição antropológica que viria a apresentar Oliveira Viana, meio século depois. Não obstante a diferença do diagnóstico quanto às causas da ausência, a passagem seguinte bem poderia ter saído da pena de Viana: "O vício orgânico dos homens neste país, vós o sabeis, é a ausência de autonomia. 0 brasileiro não se sente independente e livre, não se dispõe a vagar nos mares da vida contando só com a sina da sua estrela e os ventos da sua fortuna, não resolve caminhar senão apoiado nalgum braço protetor." (VIANNA, 2004, p. 16).

Em busca da superação deste homem, viciado na heteronomia e corrompido por um governo identificado como um "oráculo sagrado" ou uma "divindade protetora" (BASTOS, 1975, p. 39), a solução liberal de Tavares Bastos torna turvas as linhas que separam o doutrinário do político atento às especificidades do caso brasileiro.

Dado que a centralização não realiza nem o principal fim a que se propõe, qual seja, o de evitar as "tempestades revolucionárias" (BASTOS, 1937, p. 23), Tavares Bastos propõe a descentralização como o remédio mais eficaz para a consolidação das potencialidades da nação. Retirado o jugo da centralização, a autonomia provincial realizaria todas as benesses do self-government. Por um lado, portanto, a defesa intransigente da descentralização aparenta ser uma mera apropriação doutrinária do receituário tocquevilleano: 
Quais são, pois, as garantias individuais que uma lei uniforme deve firmar em todo o império? Elas resumem-se todas no nobre pensamento do século XVIII: proteger 0 cidadão contra 0 abuso do poder. 0 que é a liberdade no mundo moderno? É a efetividade da garantia pessoal e real do indivíduo. 0 fiador é o tribunal judiciário (BASTOS, 1937, p. 208).

Por outro lado, contudo, é preciso atentar para o esforço de Tavares Bastos no sentido de colocar a sua solução liberal em um lastro histórico, amenizando desta forma a carga idealista de seus postulados 5 . Aqui, o doutrinário faz apelo à tradição, e busca identificar a tarefa liberal com uma proposta literalmente reacionária: trata-se de voltar a 1831, regressar ao momento da abdicação e ao período regencial, único momento em que a nação teria podido respirar sem a hipóstase asfixiante do poder central.

Nestes termos, o embate entre liberais e conservadores é menos uma contraposição entre doutrinários e tradicionalistas, e mais uma disputa pela hegemonia interpretativa da história, uma disputa entre tradições: seria o período regencial o inferno anárquico que nele enxergam os conservadores, ou o paraíso da autonomia visto pelos liberais? Entendemos que Tavares Bastos, ao apelar para um "regresso ao espírito genuíno do ato adicional" (BASTOS, 1937, p. 112), dá um passo na direção inversa do idealismo que lhe é frequentemente imputado. 0 apelo à história e à concretude de uma experiência pretérita é evidente: "Não repudia um povo a sua história; e um partido, quando reclama liberdades que já convertera em leis, impõe-se com dobrada força ao respeito dos contemporâneos. Temos por nós a tradição liberal; contra nós o fato do absolutismo: 0 país escolherá" (BASTOS, 1937, p. 175).

0 argumento contra a uniformidade se aproxima, portanto, de uma condenação do idealismo subjacente ao apostolado da centralização. Ou seja, Tavares Bastos inverte a acusação, e defende que a plausibilidade da sua apregoada autonomia provincial está em relação direta com a maior proximidade dos fatos, das circunstâncias realmente existentes ${ }^{6}$. Querer gerar uma sociedade

\footnotetext{
5 As ambiguidades do "liberalismo brasileiro", especialmente no contexto de fins do Império, foram exemplarmente tratadas na análise clássica de Roberto Schwarz (1981) em seu "As idéias fora do lugar". Nesse sentido, o tocquevilleanismo de Tavares Bastos, seu liberalismo pragmáticoutópico, mais afeito a Benjamin Constant do que a idealismos jusnaturalistas inaptos para tempos de escravidão, seria sintoma de um momento histórico em que "as idéias liberais não se podiam praticar, sendo ao mesmo tempo indescartáveis” (SCHWARZ, 1981, p. 22).

${ }^{6}$ Para 0 argumento na direção contrária, cf. Wanderley Guilherme dos Santos (1978, p. 51).
} 
civil a partir do centro dos aparelhos de poder, este sim seria um programa idealista - "ainda quando não a condenasse a triste experiência dos povos, a centralização seria no Brasil um fato meramente oficial, sem base nas supostas relações da vastíssima circunferência do Estado com o centro improvisado pela lei.” (BASTOS, 1937, p. 35).

A antinomia entre Estado e sociedade civil permanece, contudo, precariamente resolvida na obra de Tavares Bastos. Se "o progresso social está na razão da expansão das forças individuais” (BASTOS, 1937, p. 19), o modo como a realidade do Estado deve se pôr diante da virtualidade da sociedade civil permanece em aberto. Não se trata, como interpretam alguns, de suprimir 0 Estado, repondo assim a ordem natural da dialética. Vale frisar, o publicista liberal não ignora a necessidade do governo: "a maior necessidade deste país, o seu remédio infalível, as suas esperanças mais ardentes resumem-se com razão num governo sábio e forte, qual ideamos" (BASTOS, 1976, p. 45).

0 liberalismo, em nossas terras, é talvez menos doutrinário do que pragmático; mesmo a radical defesa da descentralização não deve ser confundida com um "jurisdicismo formalista" (VIANNA, 2004, p. 167-168). É, pois, preciso reconhecer que o suposto idealismo de Tavares Bastos deve ser, no mínimo, matizado - denunciando a abstração do projeto de construção de uma sociedade a partir do Estado, o liberal devolve ao colo dos conservadores a pecha de idealista ${ }^{7}$. A uniformidade centralizadora desrespeita os fatos, além de obstruir o caminho da liberdade e dos interesses. Para Tavares Bastos, portanto, conferir esta primazia ao ator político, esta capacidade demiúrgica de plasmação das circunstâncias, é afastar-se do caminho efetivo de construção de uma sociedade ativa. A controvérsia gira, portanto, em torno da ausência e de como supri-la.

\section{VALSA-CHORO: O ESTADO COMO ATALHO EM OLIVEIRA VIANA}

No juízo de Oliveira Viana, "A província" de Tavares Bastos constitui o livro mais expressivo do que ele considera um "estado de marginalismo" das nossas elites políticas e culturais desde 1822 (VIANA, 1949, v. 2, p. 24). É, pois, contra este marginalismo que se voltará sua obra - na tentativa de alcançar a política mais apropriada ao nosso estado social. 0 erro dos marginalistas, a ilusão fundamental dos liberais, estaria em propor normativamente para o país um conjunto de fórmulas constitucionais que teriam pouca ou nenhuma capacidade

\footnotetext{
${ }^{7}$ Para uma leitura que enfatiza o componente utópico no pensamento de Tavares Bastos, ver Leão Rego (2002).
} 
de se enraizar nos costumes concretos da população brasileira. Assim, 0 liberalismo seria não apenas idealista como também elitista: "entre nós, essas belas franquezas e garantias liberais são apenas conquistas literárias de uma minoria aristocrática de oradores, publicistas e pensadores. 0 nosso povo não batalhou nunca por elas." (VIANA, 1973, p. 267).

0 apelo ao povo se dá, em Oliveira Viana, de uma maneira peculiar. Contra os liberais, iludidos com a possibilidade de construir uma sociedade a partir da Carta Constitucional, faz-se necessário apontar o seu descolamento com relação ao povo-massa. 0 autor parece mesmo, por vezes, divertir-se com 0 caráter abstrato dos projetos liberais, apontando para a contradição fundamental subjacente a seus construtos jurídicos - e a seu fracasso retumbante: "0 povomassa brasileiro - o nosso demos, na sua realidade viva - nunca os preocupou, nem hoje, nem ontem, nem anteontem, quando se metem a pensar na construção destes regimes, em que, paradoxalmente, este Demos é justamente o soberano! Só os interessam, exclusivamente, o Logos e as inscrições das Tábuas da Lei” (VIANA, 1949, v. 2, p. 21). Não obstante esta crítica, há que se ter em mente o devido lugar do povo no discurso do sociólogo fluminense: é preciso bem conhecê-lo, o que não significa que seja preciso louvarmos a soberania popular como princípio inamovível de nossos projetos políticos. Pelo contrário, trata-se de conhecer o povo brasileiro para melhor entender a sua incapacidade política.

Herdeiro do desapego com relação à política silogística, Oliveira Viana se põe, em sua principal obra, a investigar os elementos constituintes do povo brasileiro, sendo as Populações meridionais do Brasil sua fração mais definitiva e com maior centralidade no desenrolar histórico de nossos quatro primeiros séculos. A ausência, aqui, manifesta-se como sucedânea de um pretensamente concreto conhecimento da antropologia brasileira, dos caracteres elementares do homem brasileiro.

Em primeiro lugar, o pecado do liberalismo reside no seu urbanismo. A peculiaridade do contexto brasileiro, com relação aos centros europeus de onde se importam as idéias liberais, está no primado do elemento rural. Primado este que se encontra não só no demos - "o peso especifico da massa social do país é dado pelo homem de formação agrícola” (VIANA, 1973, p. 16) - como também entre os aristoi: "Nos dois impérios, os elementos dominantes na política e na Corte são já, como veremos, na sua quase unanimidade, homens de pura formação rural" (VIANA, 1973, p. 38).

É no desenvolvimento da nossa psicologia nacional ao longo da história que se encontra a chave de uma política efetiva. Caracterizados pela circunspecção e 
pelo espírito de clã, o brasileiro descrito por Oliveira Viana é, assim como 0 descrevera Tavares Bastos, apegado à sua heteronomia. Mas enquanto em Bastos a questão se resolve basicamente pela retirada do jugo, em Viana será preciso mais. A liberdade não é a melhor escola para a liberdade; a sociedade civil não está mais imanente, pronta a emergir. 0 viés sociologista constata exatamente 0 oposto, como se em Oliveira Viana a ausência fosse ainda mais aguda, pois já não há aquele plano de imanência em que, na narrativa do publicista liberal, a sociedade civil parecia adormecer.

Mas como, então, este admirador do escol conservador identifica a ausência? Ora, se para a linhagem liberal, de Tavares Bastos a Raymundo Faoro, a ausência se explica pela asfixiante presença de um ente político, seja ele o governo central ou o Estado com seu estamento dirigente, para Oliveira Viana, por sua vez, a presença que nos impossibilita de falar em uma sociedade civil brasileira está no plano da sociedade, e não acima dela. Neste ponto, encontramos a conseqüência decisiva do método histórico-sociológico do autor: está no latifúndio, e não em qualquer instância suprassocial, a causa fundamental das nossas especificidades.

A grande propriedade rural, forma predominante de ocupação desde 0 início dos tempos brasileiros, é a principal responsável, em seu centrifuguismo, seja pelo não-desenvolvimento do comércio (VIANA, 1973, p. 124), seja pela nãovinculação entre uma classe senhoril e um proletariado dos campos (VIANA, 1973, p. 131), ou ainda pela generalizada ausência de "instituições de solidariedade social no nosso povo" (VIANA, 1973, p. 155). A vastidão do nosso território, o excesso de terras, tem papel preponderante para um desenrolar histórico estranho - e esta definitivamente não é uma ausência qualquer - à luta de classes que, para Oliveira Viana, não só é "uma das maiores forças de solidariedade nos povos ocidentais, como a melhor escola da sua educação cívica e da sua cultura política" (VIANA, 1973, p. 157).

A função simplificadora do latifúndio não permite que do familismo e do espírito de clã se desenvolvam os interesses antagônicos e as particularidades conflituosas, próprias da sociedade civil tal como o mundo anglo-saxão a conheceu. Responsabilizar a política, ou os homens, por tal resultado - esta a ingenuidade sociológica que Oliveira Viana aponta no marginalismo dos liberais como Tavares Bastos. A sua narrativa vai no sentido oposto: a ausência aparece como uma decorrência necessária da nossa história, do nosso contexto social e da nossa psicologia nacional: "Culpa? Não tanto dos homens; mas, antes de tudo, da nossa própria história, das condições em que se processou a nossa formação social e política" (VIANA, 1949, p. 364). A culpa, portanto, somos tentados a 
acrescentar, está na própria terra - este talvez um dos resultados da busca pelo concreto e da obsessão pela realidade objetiva que guiam a empreitada de Oliveira Viana.

Por outros meios, portanto, chegamos mais uma vez à constatação do vazio; ou melhor, de uma série de vazios: com o sociólogo, aprendemos que "aqui não há sociedade" (VIANA, 1973, p. 160), que "o nosso meio social, hostil à sociedade privada, é também logicamente hostil à solidariedade política" (VIANA, 1973, p. 229), e, por último mas não menos importante, que "no Brasil, não existe povo no sentido político da expressão" (VIANA, 1959, p. 24).

0 dilema do liberalismo no Brasil está, pois, na ausência de uma sociedade liberal, sobre a qual a imposição de um sistema político liberal tem e deve ter, como derivações de um desvio idealista, conseqüências anti-liberais (SANTOS, 1978, p. 93). A função da política é dupla: não basta dispor de um modelo de sociedade, é preciso saber torná-lo real, saber combiná-lo com a realidade bem compreendida. Nesse sentido, é evidente que o conservadorismo de Oliveira Viana deve ser relativizado - não se trata de negar o moderno, nem tampouco de rejeitar a matriz anglo-saxônica. Autoritário instrumental ou iberista instrumental, tratase, para ele, de construir uma sociedade civil - tarefa para a qual 0 atraso brasileiro tanto impõe restrições quanto apresenta oportunidades, pela via do construtivismo político ${ }^{8}$.

Importante ressaltar, a esta altura, que o povo permanece politicamente passivo no projeto político de Oliveira Viana, não obstante o seu protagonismo social. É preciso encará-lo objetivamente, não para melhor representar seus interesses ou porque seria o povo a única fonte legítima de poder. Lembremos: aqui não há interesses, e nem tampouco povo, no sentido político do termo. Por isso, trata-se de conhecer para melhor transformar este povo informe e insolidário por excelência. Não há espaço para dúvidas quanto ao elitismo desta concepção: apesar de não se considerar um anti-liberal nem um anti-democrático (VIANA, 1947, p. 19), Oliveira Viana defende que "o grande problema das democracias é a constituição de uma classe dirigente capaz. 0 governo é essencialmente uma

\footnotetext{
${ }^{8}$ Seguimos, neste ponto, a análise de Werneck Vianna (2004, p. 183): "0 atraso resulta numa vantagem: o singular não impõe necessariamente um estatuto de menoridade à ordem nacional. Não chegaremos ao moderno como aprendizes do liberalismo, mas como inventores de uma nova ordem social".
} 
função das elites e só deve ser exercido por individualidades de elite" (VIANA, 1947 , p. 295) ${ }^{9}$.

A ambivalência deste construtivismo político sociologicamente orientado está, precisamente, no fato de que ele inicia por uma crítica ao idealismo liberal e termina postulando a construção da sociedade civil pelo alto, pela elite dirigente. 0 apelo à sociologia como melhor caminho para compreensão do passado e do presente deixa de se estender também para o futuro. Quanto a este, os atores podem se antepor aos fatos - em um aparentemente embaraçoso retorno ao idealismo que se queria suplantar. Assim, o circuito realista de conformação do político a um social que o determina pode ser invertido, e a autoridade passa a criar a nacionalidade. Parece-nos, enfim, que um certo iluminismo liberal pulsa bem forte dentro do romantismo historicista de Oliveira Viana ${ }^{10}$.

\section{FADO: RAYMUNDO FAORO E O LIBERALISMO NA ENCRUZILHADA}

Em Tavares Bastos, como vimos, a emergência de uma sociedade civil digna do nome faz apelo a um recolhimento do poder central: o problema está no plano político-institucional, e basta deixá-la respirar para a sociedade se desenvolver. Seu idealismo, portanto, está em conferir relativa prioridade causal para a instância política: a ausência se deve a uma presença, demasiado inconveniente, do governo central, do Estado. Já em Oliveira Viana, a crítica ao idealismo dos liberais se resolve pela observação do sociólogo, que encontra na sociedade as causas de seus próprios problemas e no Estado o agente capaz de uma intervenção corretora. 0 povo-massa de Oliveira Viana é suficientemente autônomo para obstruir os vínculos de solidariedade característicos de uma sociedade civil, mas não o bastante para construí-los. Nesta perspectiva, 0 idealismo residiria no primado normativo do político, em que o Estado e uma elite dirigente passariam a modelar o tecido social.

\footnotetext{
${ }^{9}$ Uma via de acesso a múltiplas leituras do pensamento de Oliveira Viana é o livro organizado por Elide Rugai Bastos e João Carlos Quartim de Moraes (1997).

${ }^{10}$ A referência, aqui, é Karl Mannheim, em "Conservative Thought”. Como avalia o autor a respeito do romantismo: "The faith in the power of reason, in the achievement of thought, is not abandoned. Only one type of thought is rejected, the immobile thought of the Enlightenment which argues deductively from one principle and simply puts together rigid concepts... Here again romantic thought merely continues, though more radically, and with new methods, the same process which the Enlightenment had already hoped to complete - the thorough rationalization of the world" (MANNHEIM, 1993, p. 339).
} 
Com Raymundo Faoro, finalmente, é como se a leitura de Tavares Bastos fosse histórica e sociologicamente turbinada, de modo tal que, num certo sentido, 0 próprio sociologismo de Oliveira Viana compusesse parte desta macroperspectiva, ou desta "semi-regressão ao infinito" a que procede a arqueologia faoriana (LESSA, 2002, p. 237). Isto é, a grande ausência da sociedade civil se deve mais uma vez ao parasitismo do Estado, mas a solução pelo mero retraimento da esfera estatal parece já pouco provável aos olhos do juristahistoriador, mesmo que continue desejável. A premissa parece, assim, ser compartilhada com Tavares Bastos: "somente a física dos interesses pode remover a velha tradição metafísica brasileira" (VIANNA, 1999, p. 177). Mas, por outro lado, esta velha tradição de tantos séculos de maturação parece se revelar de tal modo entranhada na ontologia brasileira que seria vão esperar muito destes malformados interesses - daí as "rabugens de pessimismo" deste malfadado "longínquo pesadelo" que nos apresenta Faoro em Os donos do poder (FAORO, 2001, p. 14).

Tal como Oliveira Viana, é preciso voltar no tempo e investigar as raízes da nossa precariedade ${ }^{11}$. Mas, na narrativa de Faoro, o retorno apreende 0 pecado original, antes mesmo de Pedro Álvares Cabral, nas transformações sociopolíticas do século XIV luso. Da revolução de Avis a Getúlio Vargas, a nossa história seria fundamentada numa permanência degenerativa: um estamento, por cima das classes sociais e impedindo-as de propriamente se formarem, conduz o ritmo das transformações, em um capitalismo politicamente orientado. Em suas constatações, o Weber de Faoro se contrapõe ao Durkheim de Oliveira Viana: a categoria do estamento rouba, pelo alto, a vitalidade dos laços de solidariedade próprios a uma sociedade de classes, e passamos a ter, com efeito, uma história que se desenrola como pano de fundo das ações deste macrossujeito.

A despeito desta diferença essencial entre as duas perspectivas, acreditamos ser possível pensar Faoro como uma espécie de suprassunção dialética de Oliveira Viana - como se o estatismo deste exercesse uma função negativa na versão faoriana do liberalismo herdado de Tavares Bastos. A solução deste seria ainda ingênua, posto que ignoraria a realidade sociológica do estamento; e a solução autoritária seria mais um capítulo da viagem redonda, da supressão da sociedade civil pelo Estado: "é o elitismo, uma vez e sempre o elitismo" (FAORO, 1976, p. $160)$.

\footnotetext{
${ }^{11}$ Para um aprofundamento acerca das consonâncias e dissonâncias entre Oliveira Viana e Faoro, ver Ferreira e Ricupero (2005).
} 
Em nossa hipótese da suprassunção, há que perceber a narrativa de Faoro como uma superação desencantada. A síntese, neste caso, não resolveria a antinomia sociedade civil-Estado, antes a perpetuaria como marca indelével, como enigma decifrado (porém não extirpado) da nossa constituição. Neste caso, a escolha por Machado de Assis como interlocutor privilegiado não é mera casualidade. Machado funcionaria, para Faoro, como o contraponto conservador e moralista (e nesse sentido, uma espécie de Oliveira Viana travestido de romancista) e, ao mesmo tempo, como um confirmador de algumas de suas teses gerais, tais como o primado do urbano contra um suposto ruralismo da nossa formação e a própria deformação estamental do capitalismo.

Para Faoro, portanto, a nossa dialética é capenga, a nossa história uma não-história, porque padecemos da ausência de racionalidade. 0 "espectro da irracionalidade" (FAOR0, 1976, p. 268) paira no conluio entre comerciantes e monarquia; o lamento pelo mercado que poderia ter sido lembra, não por acaso, a melancolia de Tavares Bastos. Em nossas plagas, infelizmente, "o tempo não é dinheiro; o tempo é remédio" (BASTOS, 1975, p. 13) - é a racionalidade do dinheiro que nos faz falta. No limite, este pensamento liberal parece lamentar que tenhamos colocado a consciência humana, sob a forma da autoridade, no meio do puro interesse egoísta e da abstração de uma sociabilidade intermediada pelo dinheiro.

Ora, sabemos que o lamento de Machado de Assis é outro. Para ele, o tempo é, de fato, o único remédio:

Compreendeu Machado de Assis que as prescrições de papel seriam inócuas. Não acreditou que o definhamento dos municípios fosse mera obra da vontade do grupo conservador. Cansado de perscrutar as causas de tantos malogros, voltou-se para o tempo, pai de todas as coisas, que tudo remedeia e salva. No bojo do tempo, viria a sabedoria - fórmula de cura de um homem perplexo, porém crente no país e nas suas virtudes (FAORO, 1976, p. 84-85).

Mas talvez por isso mesmo seja Machado o escolhido de Faoro: 0 realismo sociológico de Machado faz de seus contos e romances uma pertinente confirmação da história que o jurista gaúcho pretende nos contar, enquanto seu moralismo/conservadorismo é amostra visível do enraizamento de uma consciência coletiva caudatária da semiparalisia de nosso quadro social. Com a leitura que Raymundo Faoro faz de Machado em seu A pirâmide e o trapézio, 
teríamos assim um complemento à grande narrativa de os donos do poder - a obstrução da sociedade civil por um Estado estamental, patrimonialista e burocrático não apenas deforma o tipo ideal de um sistema de interesses, como ainda forma uma cerra realidade social, esta também tão persistente e talvez até mais difícil de superar do que o estamento.

É possível observarmos este duplo papel de Machado de Assis, protagonista e antagonista a um só tempo, na abordagem de três temas candentes no século XIX e centrais para a narrativa faoriana. São eles, o papel de D. Pedro II, a avaliação da burguesia e a desmistificação da libertação dos escravos.

Quanto ao primeiro, enxergamos nítida e, de novo, anacronicamente 0 Oliveira Viana por detrás da pena de Machado de Assis. Isto porque, tanto quanto para 0 sociólogo, "o D. Pedro de Machado de Assis está coroado com o mito, que 0 eleva, nas ruas, no coche, no jogo político. [...] é o mesmo D. Pedro II que vive na imaginação popular - mito que permanece intacto, incólume a um século de crítica e de análise" (FAORO, 1976, p. 57). 0 topo da pirâmide, suposto alvo primeiro de todos os ataques e ponto fundamental de equilíbrio do sistema estamental interpretado por Faoro, é louvado como o responsável pela salvaguarda de alguma ordem social. 0 que é presença asfixiante do centro em Tavares Bastos torna-se presença benfazeja e indispensável em Machado de Assis-0liveira Viana.

A burguesia, por seu turno, recebe do romancista "a tinta do desdém e do ridículo" (FAOR0, 1976, p. 7). Sua fraqueza, atribuída por Faoro à (de)formação histórica que não lhe permite ter a devida consciência de que é tudo e será tudo, aparece em Machado tanto no escárnio conservador, quanto na precisa descrição sociológica. 0 autor de Esaú e Jacó reconhece que, a despeito do seu enriquecimento, a burguesia aqui não domina nem governa (FAOR0, 1976,); e a ascensão pelo dinheiro esconde uma insuficiência, na sociedade em que a classe se inferioriza perante 0 estamento ${ }^{12}$. Enfatizando a submissão do capitalismo à política no Brasil, Faoro vê que "as personagens de Machado de Assis pouco sonham com o dinheiro, ao passo que deliram com o poder" (FAORO, 1976, p. $111)$.

Por fim, a astúcia sociológica de Machado lhe permite ultrapassar a névoa idealista dos bons princípios liberais e, mais uma vez antecipando Oliveira Viana, reconhecer que "a liberdade, a bela e milagrosa liberdade dos comícios e dos

\footnotetext{
${ }^{12}$ No enriquecimento, a subida, também filha da ambição, deixa um travo de insuficiência e pecado. Aqui, o dinheiro, que alça, eleva e doura, não dá tudo; transmite, ao contrário, o sentimento de que houve o escamoteio de quem 'fura' a entrada, sem ser convidado (FAORO, 1976, p. 14).
} 
panfletos, também ela esconde a servidão" (FAORO, 1976, p. 332). Ou seja, a astúcia do capitalismo politicamente orientado reside na sua virtual blindagem quanto a transformações emancipatórias: depois de séculos de ausência, o liberalismo bem compreendido de Faoro reconhece, junto com Machado, a ineficácia de tentativas abstratas de construção da sociedade civil. Como sair deste dilema, eis o que não se deixa revelar neste longínquo pesadelo.

\section{CONSIDERAÇÕes FinaIs}

Procuramos, ao longo deste artigo, explorar as variantes daquela que veio a se tornar uma hipótese das mais reverberadas acerca do processo de formação do Brasil, apregoando a ausência da sociedade civil. Com este fim, buscamos reconhecer os vestígios ou as imensas pegadas desta tese mesmo nas mais distintas perspectivas - e a isso se deve a aparentemente estranha convivência de Tavares Bastos ao lado de Oliveira Viana. Tomando Raymundo Faoro como momento de superação, em que o publicista liberal seria a tese e o sociólogo fluminense apareceria como antítese, ressaltamos a encruzilhada de um liberalismo para o qual a solução autonomista de Bastos parece carente de informação sociológica, enquanto o viés estatista de Viana não constitui desvio da viagem redonda de que é preciso se afastar.

A despeito das existentes refutações histórico-sociológicas da tese de Faoro, que tornam pouco plausível a apreensão da história brasileira como domínio de um macrossujeito estamental ${ }^{13}$, a sua importância está menos na acuidade científica e mais na sua força política. Sendo assim, perscrutar as teorias da ausência ganha, neste início de sexto século, uma relevância específica, no sentido de que a reconstrução do presente passa por uma necessária compreensão da relativa hegemonia atual de que parece desfrutar a tese faoriana, cujo dualismo opõe o Estado, onipotente e desajeitado tal qual um Hércules Quasímodo (FAORO, 1987, p. 55), a uma sociedade civil que, inerte e em perpétuo estado de imanência, se veria colonizada ora pelo coronelismo, no campo, ora pelo populismo, nas cidades, ou ainda, em atualização conjuntural mais recente de certo liberalismo, pelo Bolsa Família nos rincões mais pobres do país.

Contra esta suposta herança maldita de um Estado parasitário, Faoro e os seus seguidores, mesmo os inconscientes, propugnam: "para que o país progr[ida], nada mais lógico do que sampaulizar o Brasil, sob os moldes da

\footnotetext{
${ }^{13}$ Para uma leitura crítica dessa hipóstase do estamento na narrativa faoriana, cf. Fernando Henrique Cardoso (2013).
} 
iniciativa particular, e com a colaboração do capital estrangeiro.” (FAORO, 2001, p. 793). Esta rota teria sido aberta em alguns fortuitos momentos da nossa tormentosa história, apenas para logo depois vir a ser novamente abandonada, pela lógica perversa do estamento - até que veio a década de $1990^{14}$.

Configurada esta aparente vitória da tese de demonização da nossa história pregressa (LESSA, 2002, p. 243), parece-nos que a luta contra a "mercadofilia demofóbica" (LESSA, 2002, p. 243) passaria pelo reconhecimento de que a essencialização liberal da "física dos interesses" nada mais é, com efeito, do que uma metafísica entre tantas possíveis. Até porque, para além deste Weber (0 enraizado patrimonialismo) que supostamente emperra a nossa realização de Marx (ou de Hegel) (rumo a uma sociedade civil com suas lutas de classes devidamente despoluídas de vestígios estamentais), o caminho democrático da política brasileira parece desdenhar destas lastimadas incongruências entre 0 real e o modelo dialético - fazendo, assim, daquele suposto elo perdido uma abstração que, hoje mais do que nunca, obscurece a consideração do espaço, demasiadamente concreto, das disputas políticas em torno da democratização.

\section{REFERÊNCIAS}

BARBOZA FILHO, Rubem. FHC: os paulistas no poder. In: AMARAL, R. (Org.). FHC: os paulistas no poder. Niterói: Casa Jorge Editorial, 1995.

BASTOS, Aureliano C. T. A província. São Paulo: Ed. Nacional, 1937.

BASTOS, Aureliano C. T. Cartas do solitário. São Paulo: Ed. Nacional, 1975.

BASTOS, Aureliano C. T. Os males do presente e as esperanças do futuro. São Paulo: Ed. Nacional, 1976.

BASTOS, Elide R.; QUARTIM DE MORAES, João C. (Org.). O pensamento de Oliveira Viana. Campinas: Ed. Unicamp, 1997.

BRANDÃO, Gildo M. Linhagens do pensamento político brasileiro. São Paulo: Aderaldo \& Rothschild, 2007.

CARDOSO, Fernando H. Pensadores que inventaram o Brasil. São Paulo: Cia. das Letras, 2013.

\footnotetext{
${ }^{14}$ Sobre a vitória do projeto de "sampaulização" do Brasil na década de 1990, ver "FHC: os paulistas no poder", de Rubem Barboza Filho (1995).
} 
FAOR0, Raymundo. Existe um pensamento político brasileiro? Estudos Avançados, São Paulo, v.1, n. 1, out./dez. 1987.

FAORO, Raymundo. Machado de Assis: a pirâmide e o trapézio. São Paulo: Ed. Nacional, 1976.

FAORO, Raymundo. Os donos do poder. São Paulo: Globo, 2001.

FERREIRA, Gabriela N. Centralização e descentralização no império: o debate entre Tavares Bastos e visconde de Uruguai. São Paulo: Ed. 34, 1999.

FERREIRA, Gabriela N.; RICUPER0, Bernardo. Estado e sociedade em Oliveira Viana e Raymundo Faoro. Cadernos do CRH (UFBa), Salvador, v. 18, 2005.

HEGEL, Georg W. F. Princípios da filosofia do direito. São Paulo: Martins Fontes, 2003.

JASMIN, Marcelo G. A viagem redonda de Raymundo Faoro em Os donos do Poder. In: ROCHA, J. C. C. (Org.). Nenhum Brasil existe. Rio de Janeiro: Topbooks/UERJ/Univercidade, 2003.

LESSA, Renato. Revisitando Faoro: o longínquo pesadelo brasileiro. Travessias, Rio de Janeiro, n. 2/3, 2002.

MANNHEIM, Karl. From Karl Mannheim. New Brunswick: Transaction, 1993.

MARX, Karl. A ideologia alemã I. Lisboa: Editorial Presença; Martins Fontes, 1980.

MARX, Karl. A questão judaica. In: . Manuscritos econômico-filosóficos. Lisboa: Edições 70, 1989.

REG0, Walquíria D. L. A utopia federalista. Estudo sobre o pensamento político de Tavares Bastos. Maceió: EDUFAL, 2002.

SANTOS, Wanderley G. Ordem burguesa e liberalismo político. São Paulo: Duas cidades, 1978.

SCHWARZ, Roberto. Ao vencedor as batatas. São Paulo: Duas Cidades, 1981.

VIANA, Oliveira. Instituições políticas brasileiras. Rio de Janeiro: José Olympio, 1949. v. 2.

VIANA, Oliveira. O ocaso do império. Rio de Janeiro: José Olympio, 1959.

VIANA, Oliveira. Populações meridionais do Brasil. Rio de Janeiro: Paz e Terra, 1973.

VIANA, Oliveira. Problemas de política objetiva. São Paulo: Ed. Nacional, 1947. 
VIANNA, Luiz W. A revolução passiva. Rio de Janeiro: Revan, 2004.

VIANNA, Luiz W. Raymundo Faoro e a difícil busca do moderno no país da modernização. In: BOTELHO, A.; SCHWARCZ, L. (Org.). Um enigma chamado Brasil: 29 intérpretes e um país. São Paulo: Cia. das Letras, 2009.

VIANNA, Luiz W. Weber e a interpretação do Brasil. In: SOUZA, J. (Org.). O malandro e o protestante. Brasília: UnB, 1999. 